\title{
Rational maintenance and management of heating networks of the city
}

\author{
Julia Vorobyeva ${ }^{1, *}$, Igor Zhutaev ${ }^{1}$, Yuri Trukhin ${ }^{1}$, and Nadezhda Chaika $^{2}$ \\ ${ }^{1}$ Voronezh State Technical University, 14, Moscow Avenue, 394026, Voronezh, Russia \\ ${ }^{2}$ Moscow Aviation Institute, 4 G, Volokolamsk sh., 125080, Moscow, Russia
}

\begin{abstract}
The solution of specific tasks of management and rational maintenance of energy systems of cities can be ensured by a constantly updated unified urban geographic information system. The article discusses the main possibilities of using geographic information systems to determine the reliability indicators of heat supply networks, increase their efficiency and manageability by the processes of their operation. The analysis of the technical condition of the heat network of the city of Voronezh, the statistics of accidents and repair work on sections of the pipeline. The main shortcomings of the existing reliability accounting system, which does not imply the process of managing repair and restoration work, are identified. The expediency of making operational decisions on the basis of up-to-date information on the condition of sections of the heating network in different areas of the city and different periods of installation and repair is proved. The necessity of creating a constantly updated, updated and updated database of all systems of the city of Voronezh using geographic information technologies is justified. The analysis of factors leading to the need for reconstruction of heat supply systems is carried out. It has been established that the most common reasons leading to the need for reconstruction of heat supply systems are: change in the number of connected consumers; change in flow, temperature or pressure in the heating network; mismatch of energy indicators of the system with modern requirements.
\end{abstract}

\section{Introduction}

Today, the main task in servicing and operating engineering networks in all cities of Russia is to obtain information about the state of the system in near real-time mode, process various parameters, and select optimal management solutions for their trouble-free operation. In the case of a shortage and lack of the ability to quickly search and analyze information, it leads to a decrease in the reliability of systems and further accidents [1-4]. In addition, the constantly changing working conditions of the engineering system are the rationale for the reconstruction or modernization of its individual elements. In works [5-7], the main reasons leading to the need for reconstruction of heat supply systems were analyzed, among which:

- change in the number of connected consumers;

\footnotetext{
* Corresponding author: cccp38@yandex.ru
} 
- change in the estimated flow rate of the coolant;

- change in the calculated parameters of the coolant (pressure or temperature) in the heat source;

- mismatch of energy indicators of the system with regulatory requirements;

- inconsistency of the system circuit design with the requirements of effective regulation of heat supply to consumers.

The solution of specific tasks of management and rational maintenance of energy systems, including heat supply to cities, can be ensured by a single urban geographic information system [8-13]. Modeling the consequences of emergencies when using information technology allows you to optimize actions to address them in real conditions. To do this, first of all, a vector address plan is compiled in the form of polygons, streets and other objects, which requires not only accurate execution, but also constant updating of information. Further, an exchange of information between the municipality and the organizations serving the systems is necessary, the purpose of which is to obtain relevant information by the parties.

In many cities of Russia, there is already a positive practice of using the urban information system, which allows analyzing thermal and other engineering systems for their effective operation and maintenance, the need for repair work, as well as maintaining up-to-date information on various engineering communications at any stages of it existence [3-7].

\section{Experimental}

In this work, heating networks in the city of Voronezh were considered as an object of study. District heating networks in Voronezh have a complex branched structure and considerable length (Fig. 1). The length of the heating networks of the city of Voronezh is $800 \mathrm{~km}$.

Analysis of the state of the heat supply system showed that pipelines are the most vulnerable elements of the system. The degree of wear of the main pipelines of Voronezh approached $50 \%$, and the quarterly and distribution pipelines exceeded $80 \%$ [3-4]. The technical condition of pipelines requires reconstruction and replacement, as the age of some sections of the network reaches 60 years. The main amount of damage to heating mains is caused by the aging of the metal due to the long service life. Diagnostics of the state of the pipeline can be based on statistics on accidents that have already occurred, or on the basis of discretization of some theoretical relationships that determine operational aging and the corresponding change in the characteristics of the pipeline [2].

At the moment, there is no centralized service in Voronezh responsible for geodetic surveys of under construction or repaired engineering services, and there is no systematic data exchange between utilities, which complicates emergency repairs.

Recently, in many regions of the country there has been a steady tendency towards a decrease in the reliability stock of heating networks laid down during construction. The consequences of this are excessive consumption of thermal energy, loss of coolant, high costs for the restoration and repair of the system, violation of normal living and working conditions of people. 


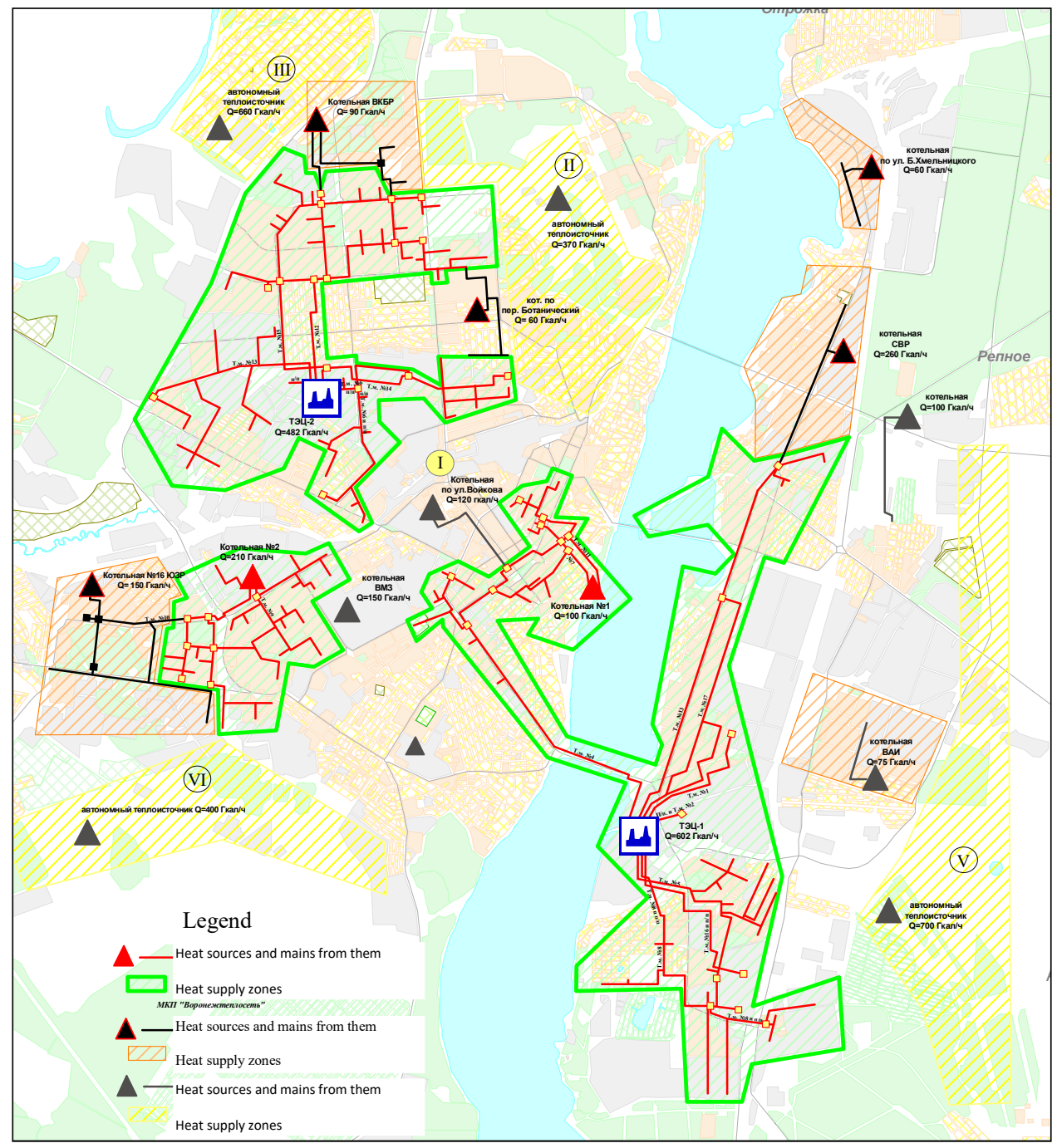

Fig. 1. The scheme of district heating of the city of Voronezh.

To get out of this situation while ensuring the reliability of the heat supply in Voronezh, it is necessary to use a unified technology for accumulating spatial information during repairs, reconstruction and new construction of heating networks, which allows simulating the consequences of emergencies and optimizing switching actions bypassing damaged sections of the network. This can be achieved by abandoning the traditional file storage of information and moving to geographic information systems built on the principle of a single repository of spatial and descriptive information based on the DBMS [13].

For the costs of implementing GIS to be recouped, it must contain an attributive, methodological and instrumental basis for solving the following most common tasks [14]:

- graphic representation of the scheme of engineering networks with reference to the city plan;

- inventory of distributed infrastructure of utilities;

- providing certificates and generating reports on the engineering network;

- forecasting and modeling of emergencies, monitoring the status of networks and preventing emergencies; 
- hydraulic calculations, adjustment calculations of consumers and calculation of heat losses;

- regulation and optimization of energy consumption;

- archiving, analysis and graphical display of damage (defects) on the network;

- operational dispatch control and provision of preventive and emergency repair work;

- technological calculations (load conditions, losses in utility networks, etc.);

- tracking, simulation and testing of switching.

Analyzing the capabilities of various GIS, it is proposed that the Autodesk MapGuide system equipped with an access tool to Oracle and developed by CSoft (www.csoft.ru) based on an Internet browser, the specialized components of the UtilityGuide software package: EnerGuide (monitoring) as a tool for working with heating networks in Voronezh electricity networks), WaterGuide (for monitoring water supply and sewerage networks), HeatGuide (for monitoring heating networks) and GasGuide (for monitoring gas supply networks). Their interface takes into account the complex data structure and allows you to more quickly and efficiently obtain the necessary information about the state of the network, build analytical queries of any degree of nesting [9].

\section{Evaluation}

Heating networks in a centralized heat supply system are spatial non-linear network structures with an arbitrary topology and a large number of consumer nodes having a heterogeneous heat load (heating, ventilation, hot water supply, technological processes) and presenting different requirements for the reliability of heat supply. An important property of heating networks is the low probability of a complete system failure.

An analysis of the state of heating networks using the example of the city of Voronezh showed that the reserves of reliability of heat supply depend on the design features of heating networks, their length and methods of operation. The network is characterized by the presence of significant differences in the requirements for the reliability of heat supply from consumers of different categories, the unevenness of the processes of heat consumption, a variety of technical means of ensuring reliability [15].

Based on the data on the failure rate of sections of the heating network, the repeatability of outdoor temperatures and the data on the recovery time of the sections, heating networks, the probability of failure of the heat supply to the consumer was determined.

To describe the parametric dependence of the failure rate $\lambda, 1 /(\mathrm{km}$ year $)$, we use the dependence on the service life, of the following form, similar in nature to the Weibull distribution:

$$
\lambda(\mathrm{t})=\lambda_{0}(0,1 \tau)^{\alpha-1}
$$

where $\tau$ is the life of the site, years; $\lambda$ o-weighted average frequency (intensity) of steady failures for a specific heat supply system $1 /$ (km per year), $\alpha$ - empirical coefficient [16].

In the absence of reliable data on the recovery time of heat supply to consumers, we use the dependence obtained empirically for the time required to repair the damage proposed by E. Ya. Sokolov [16]:

$$
\mathrm{z}_{\mathrm{p}}=\mathrm{a}\left[1+\left(\mathrm{b}+\mathrm{cl}_{\mathrm{c}}\right) \mathrm{D}^{1.2}\right]
$$

where a, b, c are constant coefficients depending on the method of laying the heat pipe (underground, above ground) and its design, as well as on the method for diagnosing the place of damage and the level of organization of repair work; 
$1 \mathrm{c}$ - the distance between the sectioning valves, $\mathrm{m}$; $\mathrm{D}$ is the nominal diameter of the pipeline, $\mathrm{m}$

In accordance with the methodology [16], the calculation of the probability of failurefree operation of several highways with the following characteristics was selected:

- laying years: 1969, 1965, 1975, 1980, 1986;

- the prevailing type of heating network laying: underground in an impassable channel with wrapping insulation with mineral wool plates;

- The total length of the heating networks is $35.8 \mathrm{~km}$.

As an illustration of the calculations (Fig. 2,3) shows the dependencies of the probability of failure-free operation for two main directions.

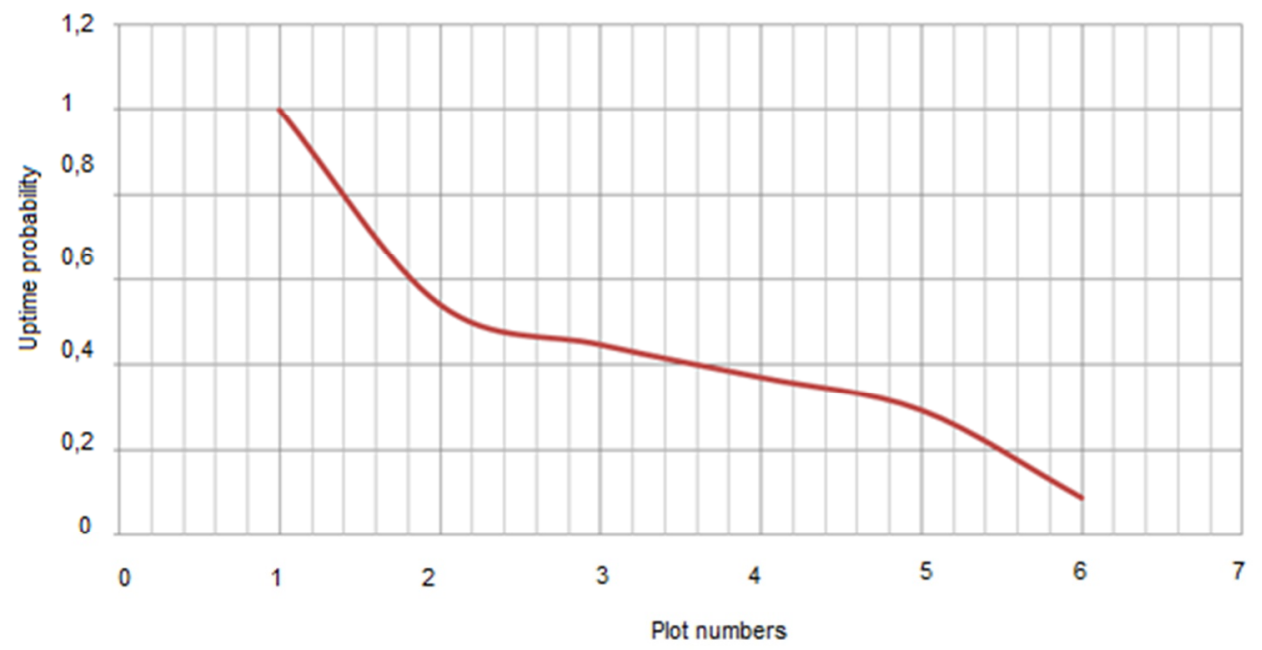

Fig. 2. The probability of failure of the heating network, settlement route No. 2 (average laying year 45 years, length $3.1 \mathrm{~km}$ ).

In general, the calculation results show that the probability of trouble-free operation in some areas of the main heat pipelines does not exceed 0.3 , and in some even less (with a standard value of 0.9 ).

Such results of operational reliability are explained, first of all, by the almost complete exhaustion of the physical resource of heating networks.

For efficient operation of the network, it is necessary to develop a strategy for reconstruction of heat pipelines, based on the gradual replacement of the most worn sections of the main heat pipelines, established by calculating the actual values completely and gradually bringing the reliability of heat supply to consumers to the standard values for each of the existing pipelines.

Since the reasons leading to the reconstruction needs are different and affect various elements of the heat supply system, a separate algorithm for making reconstruction decisions was developed for each specific case. 


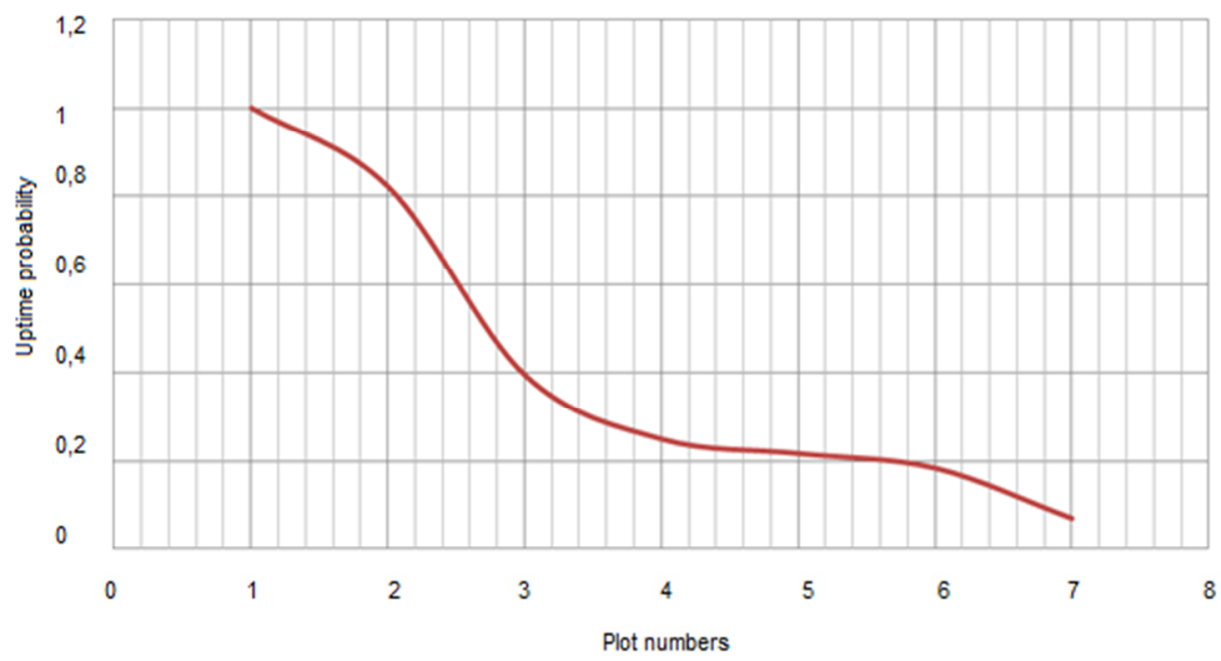

Fig. 3. The probability of failure of the heating network, settlement route No. 3 (average laying year 48 years, length $2.4 \mathrm{~km}$ ).

One of the common options leading to the need for reconstruction of the heating network is the case when a new building is being built into an existing building, connected to the existing heating system. In this case, the need for reconstruction is determined on the basis of a verification hydraulic calculation, which shows how pressure losses in the network will change with increasing flow rate of the coolant.

It should be noted that the throughput of heating networks can allow the connection of new consumers without changing the diameter of the pipes. If the diameter of the pipelines does not change, it may be necessary to adjust the settings of the regulating devices for consumers.

Another common measure for the reconstruction of intra-quarter heat supply systems is the transfer of heat exchangers for heating hot water from central to individual heating units of buildings [17].

If corrective measures do not help, then to ensure the delivery of the required amount of heat to consumers, the following technical solutions can be used:

- installation of additional circulation pumps for consumers;

- an increase in the diameters of the pipes of the heating network.

A comparison of the costs of implementing the above options will determine the most rational.

\section{Conclusions}

1. With the heat supply system existing in the Russian Federation, the main characteristic of which is centralization, underground and non-channel laying, large length and deterioration of the pipeline, it is impossible to solve the problem of ensuring its reliability without using information management technologies.

2. The composition of this GIS should include a digital map of the controlled area, internal attribute tables, an external database containing constant and accumulated information about the state of controlled objects.

3. When identifying the main reasons leading to the need for reconstruction of heat supply systems, it is necessary to establish the relationship of the elements of the system. It has been established that the most common reasons justifying the reconstruction of heat supply 
systems are: change in the number of connected consumers; change in flow, temperature or pressure in the heating network; mismatch of energy indicators of the system with modern requirements.

\section{References}

1. M.S. Kononova, A.V. Dunaeva, T.S. Logunova, A.N. Malysheva, Actual directions of scientific research of the XXI century: theory and practice 10(36), 275-278 (2017)

2. M.S. Kononova Algorithm for assessing the state of heating, Series Information technology in construction, social and economic systems 2(8), 104-107 (2016)

3. G.M. Khasanov, A.R. Zalyalova, G.M. Akhmerova, Ed. SIC "L-Journal" 1, 40-41 (2017)

4. M.S. Kononova, Computer science: problems, methodology, technology: a collection of materials of the XVII International Scientific and Methodological Conference, 218222 (2017)

5. M.N. Zherlykina, M.S. Kononova, Housing and communal infrastructure 1(4), 96-103 (2018)

6. E.I. Sheina, M.S. Kononova, Yu.A. Vorobyova, Information technology in construction, social and economic systems 1 (15), 131-134 (2019)

7. M.S. Kononova, Scientific Bulletin of the Voronezh State University of Architecture and Civil Engineering. Series: Information Technologies in Building, Social and Economic Systems 1(7), 125-129 (2016)

8. V.E. Vorotnitsky, Energoekspert 3 (2012)

9. A.M. Stavitsky, CADmaster 4, 60-63 (2004)

10. D. Proskurin Yu. Vorobeva, E3S Web of Conferences electronic edition, 02123 (2019)

11. A.V. Shpilman, I.Yu. Pogoreltseva, E.V. Ulazova, ArcReview 3(62) (2012)

12. S.V. Pavlov, A.S. Pavlov, A.S. Samoilov, Bulletin of the Ufa State Aviation Technical University 5 (58), 122-128 (2013)

13. V.P. Kupriyanovsky, P.A. Tishchenko, A.A. Seknin, R.A. Magdeev, S.I. Gerasimov M.B. Basin, Influence of data models of the CIM standard on GIS modeling of network energy enterprises (2012)

14. E.L. Isaeva, T.A. Yashina, T.A. Barbasova, Scientific research: from theory to practice, 253-255 (2014)

15. I.L. Pichugin, Bulletin of Orel State Agrarian University 4 (31), 76-80 (2011)

16. Yu.A. Vorobyova, M.S. Kononova. A.L. Mishurov, Actual directions of scientific research of the 21 st century: theory and practice 6 (42), 64-66 (2018)

17. V.A. Chernyshova, A.F. Salakhova, G.M. Akhmerova, Ed. SIC "L-Journal" 4, 71-73 (2017) DOI 10.18411/lj-30-11-2017-4 